\title{
Achieving Quality in Research through Stimulated Publication Technique
}

\author{
Mohammad Syuhaimi Ab-Rahman ${ }^{1,2}$, Shahrom Md Zain², Mohd Jailani Mohd Nor ${ }^{3}$, Ahmad Kamal Ariffin \\ Mohd Ihsan $^{3}$, Azamin Zaharim ${ }^{5}$, Muhamad Fadhil Sukarna ${ }^{2} \&$ Afiq Hipni ${ }^{2}$ \\ ${ }^{1}$ Department of Electrical \& Electronical Engineering, National University of Malaysia, UKM Bangi, Malaysia \\ ${ }^{2}$ Research Advancement Strategy \& Planning (RASP), National University of Malaysia, UKM Bangi, Malaysia \\ ${ }^{3}$ Department of Mechanical and Material Engineering, National University of Malaysia, UKM Bangi, Malaysia \\ ${ }^{4}$ Center of Engineering Education, National University of Malaysia, UKM Bangi, Malaysia \\ Correspondence: Mohammad Syuhaimi Ab-Rahman, Department of Electrical and Electronical Engineering, \\ National University of Malaysia, 43600, UKM Bangi, Malaysia. E-mail: syuhaimi1977@gmail.com
}

Received: March 10, 2013 Accepted: April 10, 2013 Online Published: December 30, 2014

doi:10.5539/ass.v11n3p14 URL: http://dx.doi.org/10.5539/ass.v11n3p14

\begin{abstract}
Quality and Quantity (Q\&Q) of researches is one of the relevant criteria in the assessment of research university (RU) and this can be seen through the status of publication in a certain universities (number of the publication in indexed journal and citation). The main purpose of writing and publishing is to publicize research findings and share knowledge gained with other researchers in their respective fields of research. Research quality can be indicated by index database ISI WOS and SCOPUS and also impact factor which refers to terms and quotes (citation). Principles and standards for quality research design are can be determined in texts, reports, essays and guides to research design and methodology. Quantity of research is evaluated by the amount of indexed journals with impact factor. This suggests that achieving only one or two stands is typically insufficient to assert quality. Researcher work has value when it is judged by peers to have merit sufficient for acknowledgement in a new text article. By the way, a specific standard that will ensure quality research, the more research studies are aligned with or respond to these principles, the higher the quality of research. This paper discusses the strategy that can be applied to maximize journal publication by means of stimulation technique. In the end of the study, we analyze the student feedback on the quality in supervision towards achieving high quality in research for pure and social science students.
\end{abstract}

Keywords: Research University, publication, effective supervision, social science, pure science

\section{Introduction}

Research University (RU) is a public university which had been recognized by the Cabinet on 11 October 2006 to become a hub of excellence for education and research. In the beginning, Research University consists of the four public universities, namely Universiti Kebangsaan Malaysia (UKM), Universiti Malaya (UM), Universiti Putra Malaysia (UPM), Universiti Sains Malaysia (USM) and finally, Universiti Teknologi Malaysia (UTM) which had been recognized as an RU on 2010. In the move towards gaining an RU status, it is imperative that the performance of the local universities be monitored and audited so that the RUs can be benchmarked against internationally well renowned universities. It is also imperative that the criteria designed would address the philosophy, vision and objective of being an RU and the standards are met. Characteristics of RU are;

(1) Study fields focusing on research,

(2) Competitive entrance,

(3) Excellent faculty (academic researchers) and also

(4) Ratio of undergraduates and postgraduates is 50:50.

Goals of RU establishment are:

(1) Increasing research and development and commercialization (R \& D \& C),

(2) Increasing intake of postgraduate and post-doctoral students, increasing the number of academic researchers who have acquired $\mathrm{PhD}$, 
(3) Establishing and strengthening centers of excellence and Enhancing the recruitment of foreign students and boosting the position of ranking in the international institutions of higher learning.

RU vision is directly focused to actively participate in the exploration of new ideas, experiment innovative ways to take the initiative on intellectual property and to continue to explore and develop advanced knowledge while RU mission is becoming the engine of growth for the country, providing opportunities for students and scholars to exchange ideas as well as research in a conducive atmosphere to spur exploration and creativity to explore science and wealth, and ultimately increase the quality of life.

Scenario research culture has grown rapidly and has increased since the implementation of the agenda research university (RU), which until today the country had five research university (RU) and the recognition of the Higher Education Centre of Excellence (HiCoE), as well as Fundamental Research Grant Scheme Fund (FRGS) available which started in 2006 which was originally received funds from the government under the Ninth Malaysia Plan 9. The strategy to increasing research capacity in the Ministry of Higher Education is continued from the year 2009 when the focus of research by empowering quality management system of research funds FRGS (Fundamental Research Grant Scheme) which have received ISO 9001:2008 certifications began in October 2009. Therefore, the research project application evaluation process, monitoring and reporting progress has been further enhanced and made periodically throughout the year. Research University also transform Malaysia as a leader in research and development (R\&D) and innovation and the production of intellectual human capital that can contribute to economic growth. In addition, recognition as a university of research will encourage local universities to compete globally and increase the ranking in the international ranking.

\section{Criteria}

\subsection{Criteria in the Selection of $R U$}

The recognition of a RU is based on eight selection criteria as approved by the Committee of Research University Assessor, in which these criteria are focusing on R \& D \& C aspects and also adopted the criteria that have been adopted by several leading international rating agencies. Scoring criteria are as follows in Figure 1 . Hopefully the recognition of the four universities in Malaysia, UKM, UM, UPM, USM and also the new one UTM as RU can be a stepping stone in efforts to develop strategies to enhance and strengthen the local institutions of higher learning at the international level. Thus, RU must work harder to improve the position or ranking among the world's top universities such as the rating THES (The Times Higher Education Supplement). This requirement is in line with the National Higher Education Strategic Plan (PSTPN) which aims to be at least three institutions of higher learning listed among the 100 best universities of the world and one of the world's top 50 universities by 2020 .

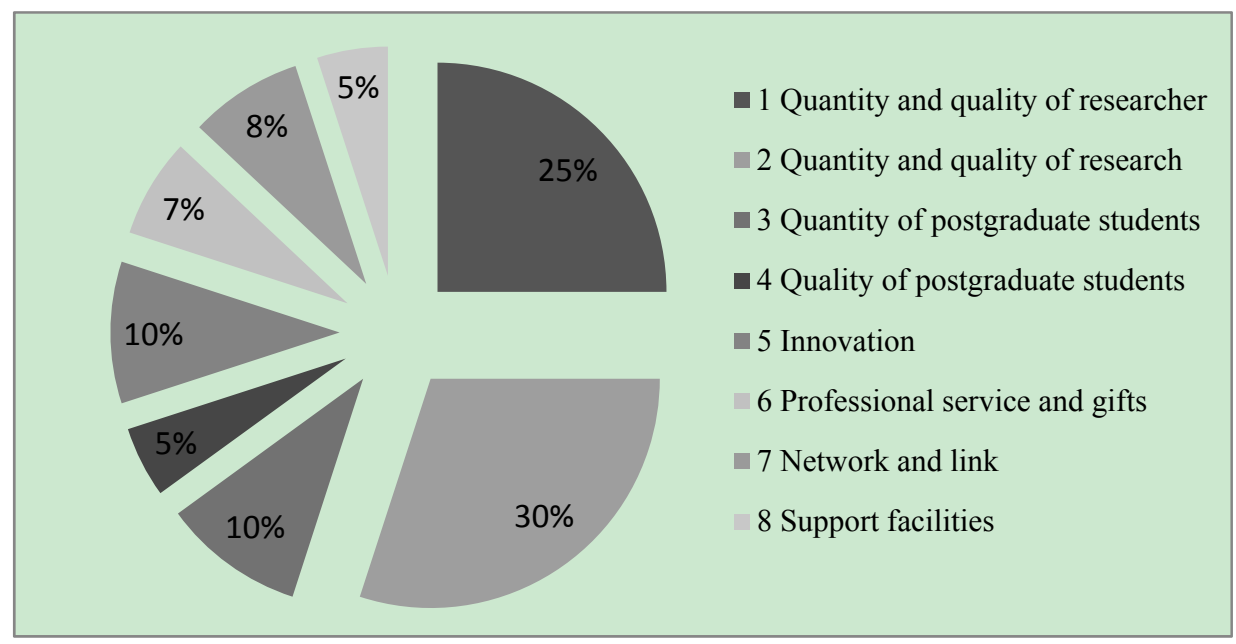

Figure 1. Criteria in the selection of RU

One of the methods to maintain RU status is to ensure all academic members conduct research and publish academic journals. Most of the academic papers are published in journal article and book formats. In journal publication, some researchers feel that journal impact factor should not be used to assess the quality and performance of a research. It is more appropriate to measure the quality of journals in certain fields such as medicine and biomedicine. Under dilemma, all members regardless of their academic research must comply with the KPI which obliges professor must have at least three journals that are indexed and high-impact within one 
year, two for associate professors and one for academic researchers (Jusoff, 2008). Basically, two methods are used to evaluate the research quality which are H-Index and Impact Factor. Both parameters used to determine the number of citation of individual (university, country and etc) and Journal. The higher citation is the more influence of one research to the other research. If the H-Index is 10 gives meaning that 10 articles have been cited at least 10 times in other publications.

An impact factor is one measure of the relative importance of a journal, individual article or scientist to pure science and also social science. Each index or database used to create an impact factor uses a different methodology and produces slightly different results, revealing the importance of using several sources to judge the true impact of a journal's or scientist's work (Garfield, 2006). As can be seen, the impact factor can be improved by increasing the number of citations, by reducing the number of source items or both. Perhaps the most important and recent use of impact is in the process of academic evolution. The impact factor can use to be providing a gross approximation of the prestige of journal in which individuals have been published. This is best done conjunction with other considerations such as a peer review, productivity and subject specialty citation rates. As a tool for a management of library journal collections, the impact factor supplies the library administrators with information about journal already in the collection and journals under consideration for acquisition. This data must also be combined with cost and circulation data to make rational decision about purchases of journals (Baker, 2004).

The impact factor of a journal is a probably the only quantitative way of assessing its worth and relevance to the academic community it serves. To merit inclusion in the ISI database and therefore to receive an impact factor, a journal must pass a vetting procedure which begins with an in house editor with appropriate subject expertise and concludes with a review and confirmation by the entire editorial team (Jusoff, 2008). ISI staff search the reference lists of all the journals they cover and count all the citations to record a total for each destination journal. The cited journals are the analyses to determine the number of articles they contain that can be considered substantial enough to warrant being counted as source items. The analysis of the cited journal is done using the online version of the journal contents list wherever possible (Kurien et al., 1999).

Impact factor also provide rough and ready guidance. As the pursuit of science has evolved from a pastime of the proper upper classes to a full blown industry, citations have become more importance and also obsession. Now, researchers worry about their places in the web of references, which they should cite and who should cite them. Researchers' council and university departments distribute money according to citation records and editors anxiously anticipate the annual announcement of their journal's impact factors. The central importance of citations to a researchers and a journals success guarantees the popularity of publications. But in the face of publication overload, researchers are forced to improve their strategies to select the reading material that is most relevant to their own work (Baker, 2004).

In counting citations, only papers published in the past two years are considered. In fact, many papers are appreciated after several years of their publication and then referred and many other papers continue influencing others' research for much longer period. Also, items such as new articles and editorials that are the regulars' features of some journals are not counted in the denominator of the impact factor but citations to those new articles maybe included the numerator, inflating the impact factor of journals that publish such articles. Now, publication of research paper or articles in reputed journal has become an important factor in assessment of the academic performance especially to assess the research university rank and also the researcher (Jusoff, 2008). Therefore, a measure such as H-index which quantifies the quality as well as the productivity of an individual author or scholar would be more appropriate than the journal impact factor. The h-index is an index that attempts to measure both the productivity and impact of the published work of an author or scholar. The index is based on the set of the scientist's most cited papers and the number of citations that they have received in other people's publications. The index can also be applied to the productivity and impact of a group of scientists, such as a department or university or country. However to achieve the H-Index increasing the Impact Factor is the main parameter one must be looking for. There are several method can be used to increase the H-Index which are publishing in prestigious journal with high impact factor (quality), Publish as many as possible in indexed journal (quantity), Networking and Promoting, and Publish own journal (be a publisher).

\section{Journal Publication as Measurement of Research Quality}

Typically, the publishing of journal articles have gone through a rigorous screening process by peer review, where independent experts provide the author with critical commentary and suggestions to improve their final paper, prior to publication. Most print journals are now widely accessible over the internet and are relatively easy for others to access. Articles submitted to journals usually appear in print sooner than books or book chapters, and continue to be accorded greater influence in promotion and tenure decisions within academia than alternative 
means of distributing information. Articles published in peer reviewed journals are likely to remain a very important means of distributing research findings for the foreseeable future.

Therefore, the assessment of many scientific journals regularly becomes the issue of academic disciplines. Academic journals serve as a forum for the introduction and presentation of new research and studies or research work of the existing comments. Common content format usually involves original research and review articles. Article rating known as an assessment of the progress of inspection or research studies published in any journal. Academic or professional publications that are not valued are known professional magazines (Ujang, 2007).

There are two visible weaknesses within academic researchers in local higher learning institutions which are peer review and reference and citation of their writings in reputable journals. Peer review is basically the viewpoints of academic community on the ability and academic contribution of the assessed academic researchers. This assessment relies heavily on writings which will be or have been published in reputable journals and active participation in international level academic activities, specifically the membership in editorial session and professional organization (Ujang, 2007).

In academic publications, peer review is very important. In addition to promotional purposes, this view is also considered for the evaluation process for the papers published in journals or books. The assessment is conducted fairly and objectively without recognizing the background writer. This is to ensure that the results are given without prejudice and comply by the academic standards. One of the main reasons for peer reviewed articles is to present a more objective research base. Every author has biases, regardless of how hard they may try to remain objective. Every peer reviewer has biases too. Having a diversity of opinions can help to neutralize the biases that may come up during research and help to keep the findings of the article objective, thus presenting the best possible research for others to build upon.

\section{Monitoring the Publication of Academic Journal}

Each institution would have a method of monitoring research publications produced, particularly journal articles. In UKM, there is an e-Publishing system that allows every member especially academic staff to record their publications, and even provides certain score for the recorded publications in accordance with the established standards. This system will be used in the next annual assessment and promotion process (Maidin, 2008). It also provides translation facilities journal articles from Malay to English to the staff university. In this regard the Malaysian national institute of translation services (ITNM) is used. Translations costs are incurred by UKM with the requirements where the journal article has to be published in journal indexed by Scopus or WOS. Editing can be done by using third-party services such as the American Journal Experts www.journalexperts.com. Articles should be published in the journal are completed (peer-reviewed). Editing costs can be claimed by the authors of these articles as soon as the papers get accepted for publication by the publisher of the journal to be completed (Maidin, 2009).

In the international rating system higher learning institutions such as THES, IOC and Shanghai Jaio Tong, the statistics used is the number of papers and citation indices in the database of ISI Web of Science (WOS) and Scopus. The purpose of evaluating quotes (or can be called citation) to the publication of this paper is to examine the impact of a publication or research project. If the citation of an institution is high, it will affect other researches.

Prior to 2007, THES used WOS as a source to obtain the paper journal citation statistics. UKM also monitored statistic of articles and quotes using WOS. The findings showed paper and citation statistics in Malaysia institutions of higher learning was low compared to institutions in Singapore and Thailand. However, when THES used SCOPUS, the number of articles and citations for institutions of higher learning in Malaysia increased. In this case, the transition from WOS to SCOPUS was beneficial for institutions of higher learning in developing countries. This was because the number of journals indexed by SCOPUS was more than WOS, especially in developing countries. Journals indexed by WOS really emphasize on the end result and objective of research. Therefore the research accepted for publication must be advanced and achieve its main goals. Unlike the journals indexed by SCOPUS which are more flexible and less severe in its rating which give opportunities to researches that are classified as advanced to be published in SCOPUS indexed journals.

\section{Strategies to Maximize Journal Publication}

The main purpose of writing and publication is to disseminate new finding and to share knowledge with other researchers in their own respective research fields. Even though a huge number of grants can be obtained, it does not indicate that all researchers will be able to publish papers in impacted journals and produce writings in books. A higher possibility is the researchers would choose the easier way by publishing their writings in conference 
which is lower in quality. Efficiency in English language can also be a factor which determines the level of writing produced by researchers because most reputable journals are in English language. In this article, the author is trying to expose a few initiatives to produce effective writings including the method to solve the aforementioned situation. There are three method groups to maximize journal publication. Starting with the system development where the supervisor is building a strong base in the lab. Enhancement activities will furthermore increase the achievable end results. Effective technique refers to the innovations applied to increase the quality of the conducted research product. Researchers have to be ready spiritually and physically before proceeding with the maximization of journal publication. Spiritually prepared means the researchers are ready to bear additional responsibility to publish any research materials and becoming a motivated person among researchers and students. Meanwhile, physically prepared means the researchers have to be hard working in achieving their goals which is to produce a certain number of journals for certain years. It is crucial for researchers to develop an efficient system which will lead to the correct path to reduce tension and confusion. This can be achieved by developing a platform to help secure the objective of the research. Important characteristics of the platform are as follows:

1. Identifying the strength and source

2. Developing Publication Generator System

3. Forming an Excellent Culture (Tip 1)

4. Practicing Effective Technique (Tip 2)

5. Hosting Enhancement Activity (Tip 3)

\subsection{Identifying the Strength and Source}

This can be done by listing down the researcher's strengths where the sources will assist in generating information and scientific data. This list is important to measure one's strength, which enables researchers to produce the next strategy in organizing manuscripts later. Figure 2 shows the examples of the strengths that can be used to generate information and scientific data. These resources have existed in a academic researcher, and subject to the review and use. More resources mean more journals can be published. Determination is the starting point because each manuscript to be developed requires the journal data either qualitatively or quantitatively. The resources are not the main problem but the question here is whether they are used effectively or not.

\subsection{Form/Develop Publications Generator System}

Generation system consists of the of four groups; the Division of Information and Data Generation, the Division of Revision and Correction, the Division of Development and the Division of Management and Monitoring. The flow chart for the development and progress of a journal manuscript is shown in Figure 3.

Division of Information and Data Generation: This is the most important part in conducting research that leads to the data and information needed. The greater this part is, the more journal manuscripts can be developed. This division is mostly composed of students and research assistants who conduct research.

Division of Revision and Correction: Completed journal manuscripts require reading by second, third and so on person to ensure that the information in the manuscripts can be delivered effectively including the use of sentences and grammar particularly manuscripts written in English language. There are many options that can be used to review and edit manuscripts and such are paid (e.g. American journal expert.com, Supaproof.com and etc.). Many agencies, companies, institutions that offer services in editing and reviewing manuscripts either journals or books are also available on the internet. For researchers who do not have a large a grant may use the services of a tutor or young academic researchers to conduct the same process. Depending on the whether the researchers wish to include the name of the editor as a researcher or pay the service with the reward money. It should be noted that the inclusion of their names in the research is important because this is the most effective way to attract young researchers to conduct research. This is called 'Nurturing the Younger Generations'. This has a positive impact on the research and branding it at either the department or faculty level.

Division of Development: The above division requires the services of young researchers (younger tutor and academic researcher as editors / reviewers) of the completed manuscript). This division also requires the expertise of senior academic researchers (e.g. Professor) to develop research products available. By viewing the results in different angles/dimensions, more analyses can be done and this will allow the project to be carried on. Multi-Dimensional Assessment (MDA), which will be discussed in the next topic in this section, can be used to optimize the research products.

Division of Management and Monitoring: The main task of researcher as an administrator is to manage the journal manuscripts that have been developed. It can also be assisted by research assistants involved in project 
management. Apart from being involved in the delivering process of the manuscripts for evaluation and monitoring of development, this division is also responsible for ensuring that all parts are smooth and successful

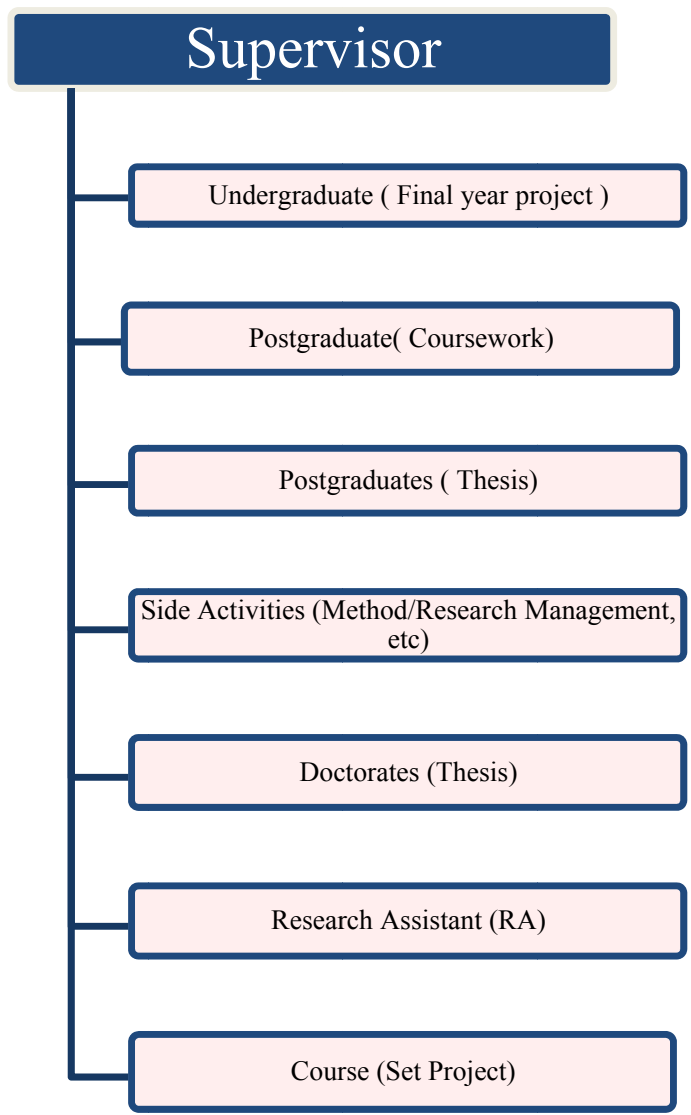

Figure 2. Examples of the strengths to generate information and scientific data

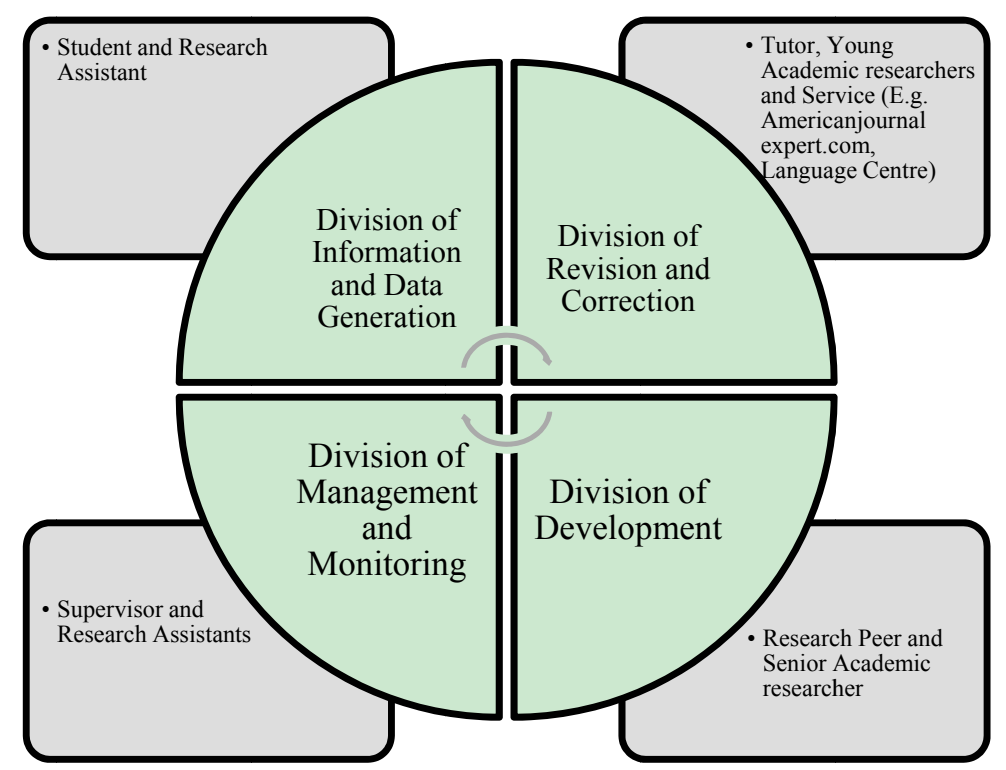

Figure 3. The flow charts for the development and progress of a journal manuscript

\subsection{Forming a Culture of Excellence (Tip 1)}

This is really important in research groups to produce students with high self-motivation. Motivated students are one of the most important aspects because they are always competing to advance their laboratory research to 
produce an output of high quality. Commitment and loyalty usually cannot be separated. Loyal students are usually alert to their supervisors' needs in order to achieve certain goals such as getting promotions and so forth. What is the most effective way to cultivate the sense of competitiveness in students? It includes self-discipline; effective monitoring and provision of facilities in the laboratory (technical and recreational) ensure that students enjoy doing research. Spending research grants wisely and effectively will help the students and they will in turn help promote the name of research groups with maximum output, including journals writing. Basically, the factors that promote culture of excellence are shown in Figure 4.

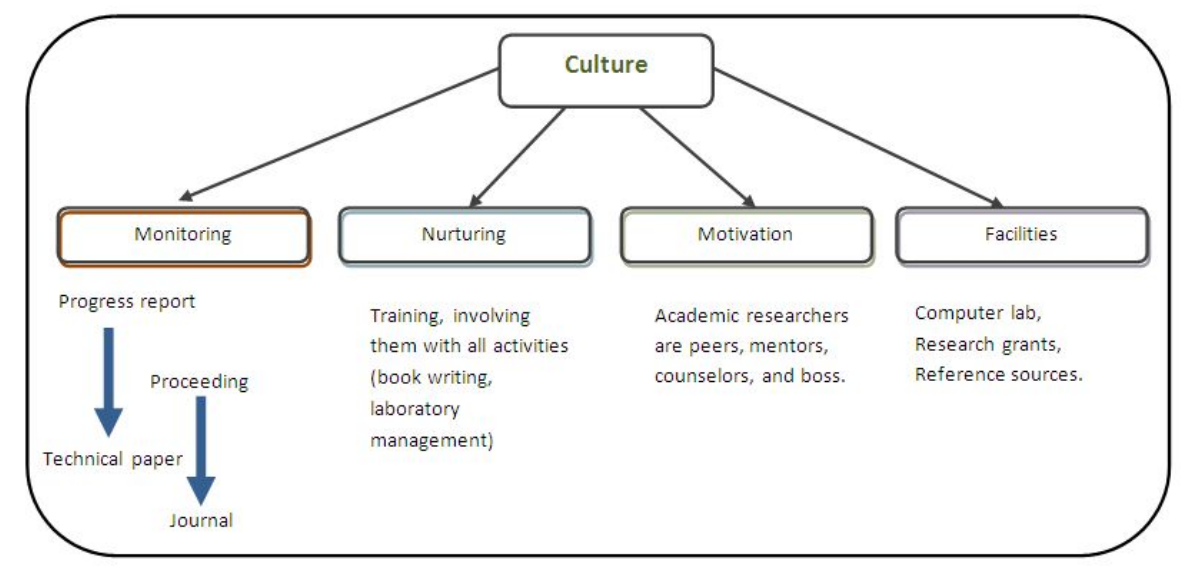

Figure 4. Factors involved in the development of cultural excellence

\subsection{Practice Effective Techniques (Tip 2)}

The application of effective techniques is crucial in maximizing the number of research although the data obtained is little. Inclusion of creative elements is very important in increasing the number and making it unique. Maximizing technical publications: Practicing effective techniques consists of Multi-Dimensional Assessment (MDA) at Research and Product Level, Inclusion of Creativity component, Express writing, Research Collaboration (double the strength of research), Integration of Multi Research and the development of database. These techniques are vital in producing a huge number of journals in a short period. Several techniques are as illustrated in Figure 5.

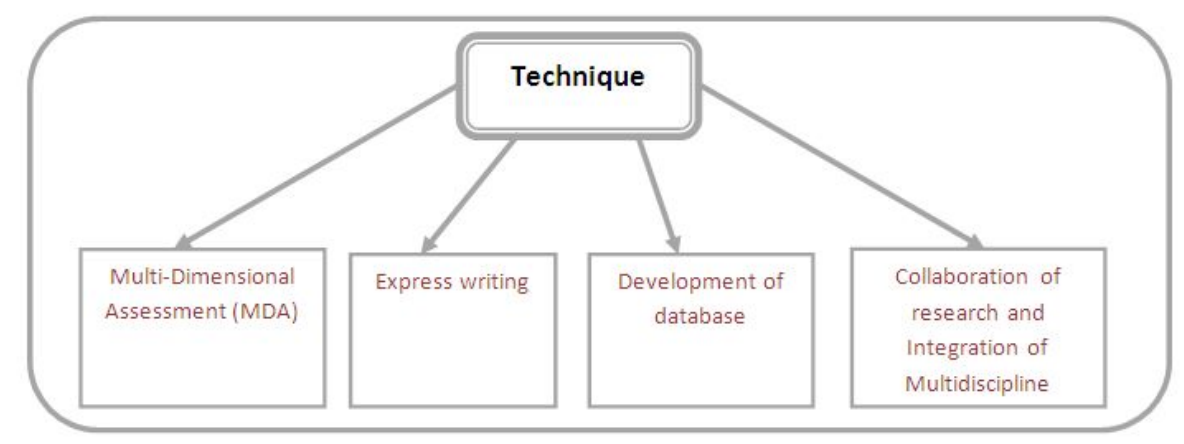

Figure 5. Example of techniques that can increase publication efficiency

\subsection{Hosting Enhancement Activity (Tip 3)}

Writing in the office or at the faculty can be tedious due to the similar environment faced every single day. The process can also be much unfocused due to distraction from other tasks. This is where publication enhancement activity works in a very effective way to produce and improve manuscripts. Supervisors can organize a 2 to 3 day event outside of the faculty that focuses on producing a number of manuscripts. The objective of this event is to produce publishable manuscripts at the end of the event. Each participant, student or research assistant is required to bring an unfinished manuscript as a 'ticket pass' for this event. Throughout the workshop, students can ask the supervisors directly if there is any confusion or discrepancy. The manuscripts should also be peer-reviewed and presented to increase their chance to be accepted and published in reputable journals. Supervisors should set the target journals early on. Examples of activities that can be organized are shown in Figure 6. Figure 7 illustrates the process for the manuscript to be published. 


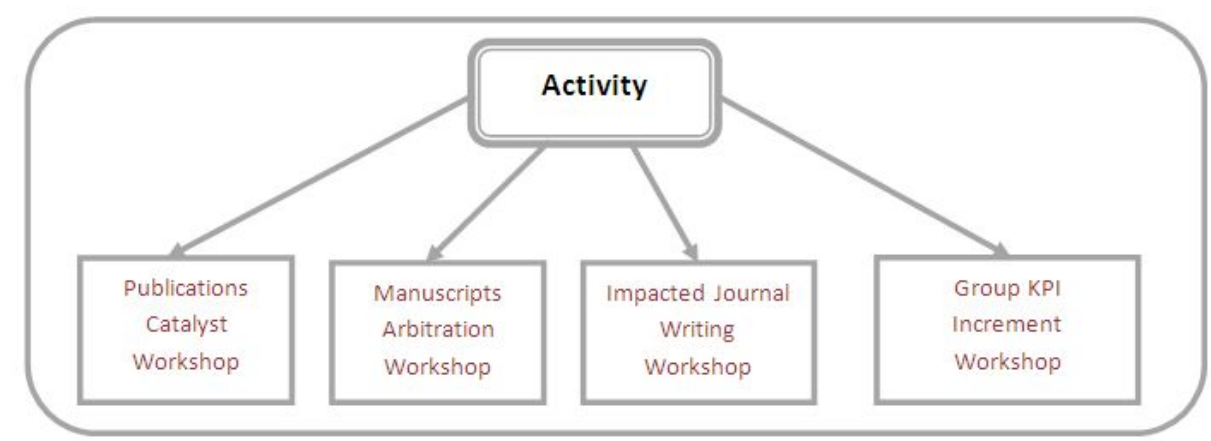

Figure 6. Example of activities to increase the quality of publication standard

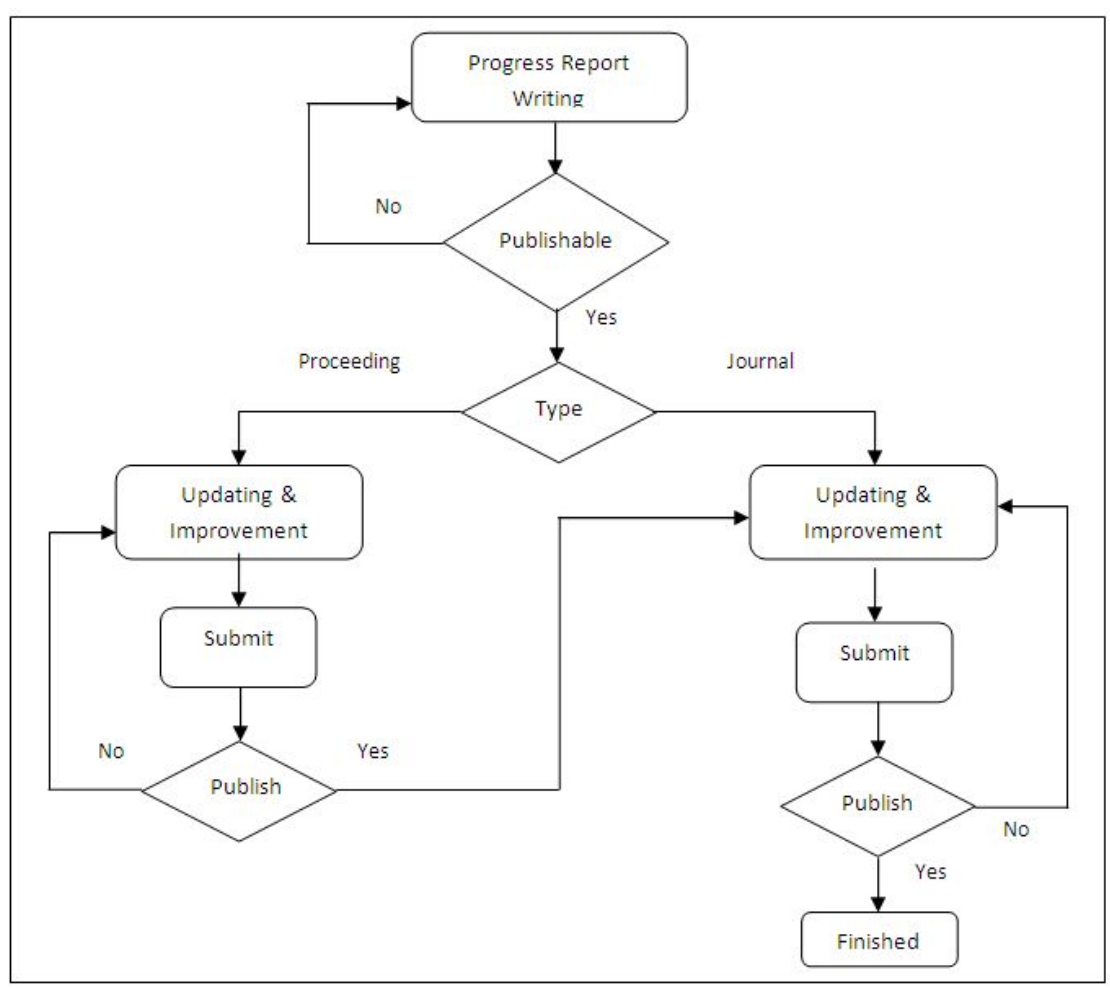

Figure 7. General flow chart of journal manuscript publication

\section{Data Analysis for Student Survey}

Figure 8 and Figure 9 show factors that affect the quality of research compared to pure science and social science. According to graph, it shows a significant different percentage about the factor affect. Indirectly, factors for affect quality research also automatically connect with the quantity in journal publishing. The graph showed that facilities are the most important things to the pure science student in their research. Facilities also are the higher affect to the pure science percentages than social students. Approximately $25 \%$ student in pure science agreed that facilities are an important requirement. Financial also showed the higher percentage with $20 \%$. It's definitely showed that pure science student needs effective monitoring and also provision of facilities in the laboratory to produce an affective publication. Facilities are important core in the formation of the system to maximize journal publishing. The facilities involving technical equipment especially, also includes effective oversight from supervisors, who have conducted research cooperation and motivation such as giving gifts or payments credit card. So, the facilities can be encapsulated in various purpose of providing important benefits to the natural sciences publish the best journal. Maximize the publication of journal also involves financial. In pure science, this is one encouragement towards the effective publications of journals such as cash rewards, honorarium and so on. Besides, remuneration research assistant (RA) and graduate research assistant (GRA) are important in achieving the mission of research universities. Application is open to all Malaysians and international admissions 
to pursue a graduate degree program with thesis or Ph.D. Each student who is appointed as Graduate Research Assistance (GRA) is responsible for assisting in teaching, tutorials and practical supervision of final year students for a period time. Therefore, provision is allowed to be used to finance tuition fees and support more postgraduate students involved in research projects.

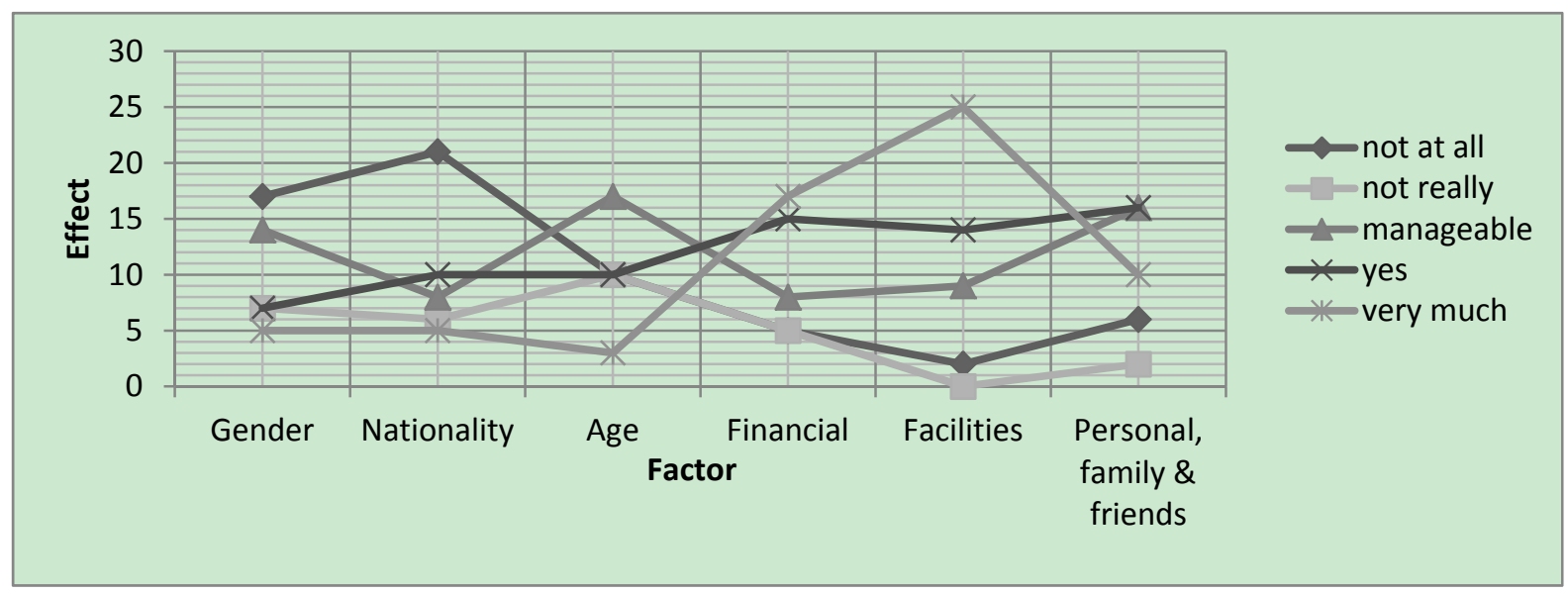

Figure 8. Graph for affect quality research of pure science

Figure 9 indicates that social science students are highly independent and they do not emphasize on the availability of a lab or facilities in order to produce journal publication. They just need guidance from supervisors and make their research from any method like oral and writing. Survey results show that most of the factors listed do not have a huge impact on social science students on their research progress. For social science, the least affected criterion is gender which is $26 \%$. For social science, the highest factor that gets 'not at all' rating is gender which is $26 \%$ and the lowest is 'nationality'. There is a huge comparison between pure science and science social. From the whole subject from survey, it show about method in research and also showed about development of cultural excellence helping students for their research and also the role of supervisor especially in pure science. Each course has different method to produce a good research.

Figure 10 and Figure 11 show the characteristics of supervisors that could affect students' research from pure and social science. In this study, respondents for pure science category are chosen from the faculty of engineering and science and technology. For social science, the respondents are from the faculty of social science and humanity and economy and business.

Figure 10 shows that pure science students appreciate patient and always available where both characteristics scored $25 \%$ for 'yes' which indicates that pure science students need a supervisor who is available and provide guidance to any research. In addition, pure science involves a lot of scientific research and laboratory experiments. They also need guidance from supervisor who is accessible and always in the laboratory. The presence of a supervisor is important in maximizing journal publication. Therefore, supervisor's characteristics that are supportive, negotiable, always available and patient are the result from pure science field. Supervisor is also a mentor who is always with students to achieve a good journal. A good mentor will be with students to achieve excellence which will keep the students momentum going. Student's motivation also is always changing, so the supervisor will help to constantly motivate students.

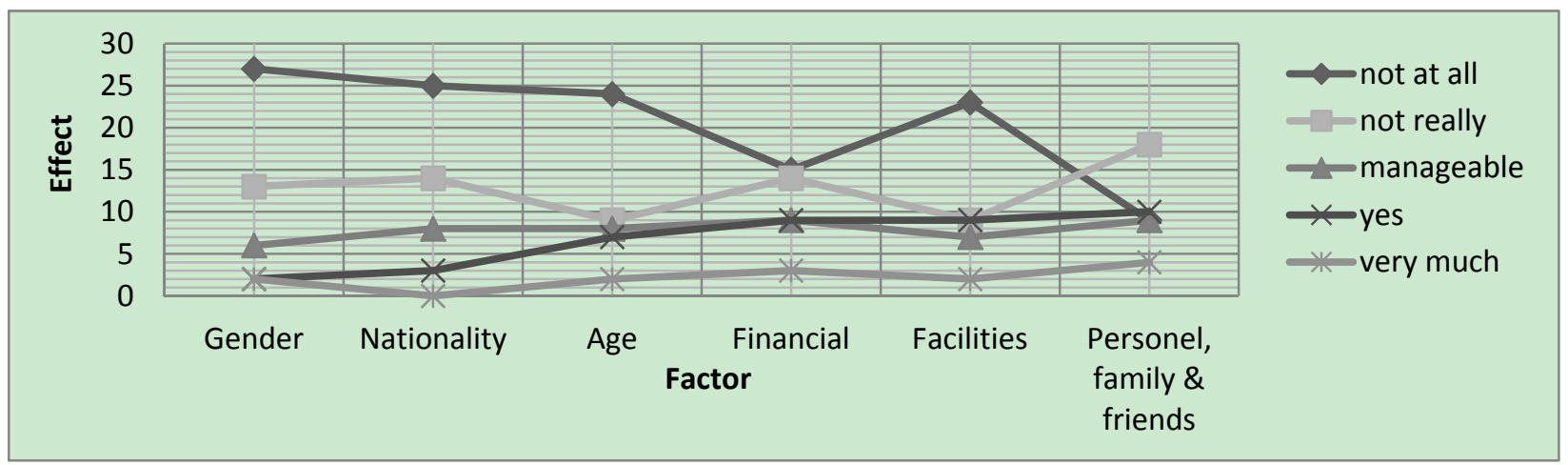

Figure 9. Graph for affect quality research of social science 


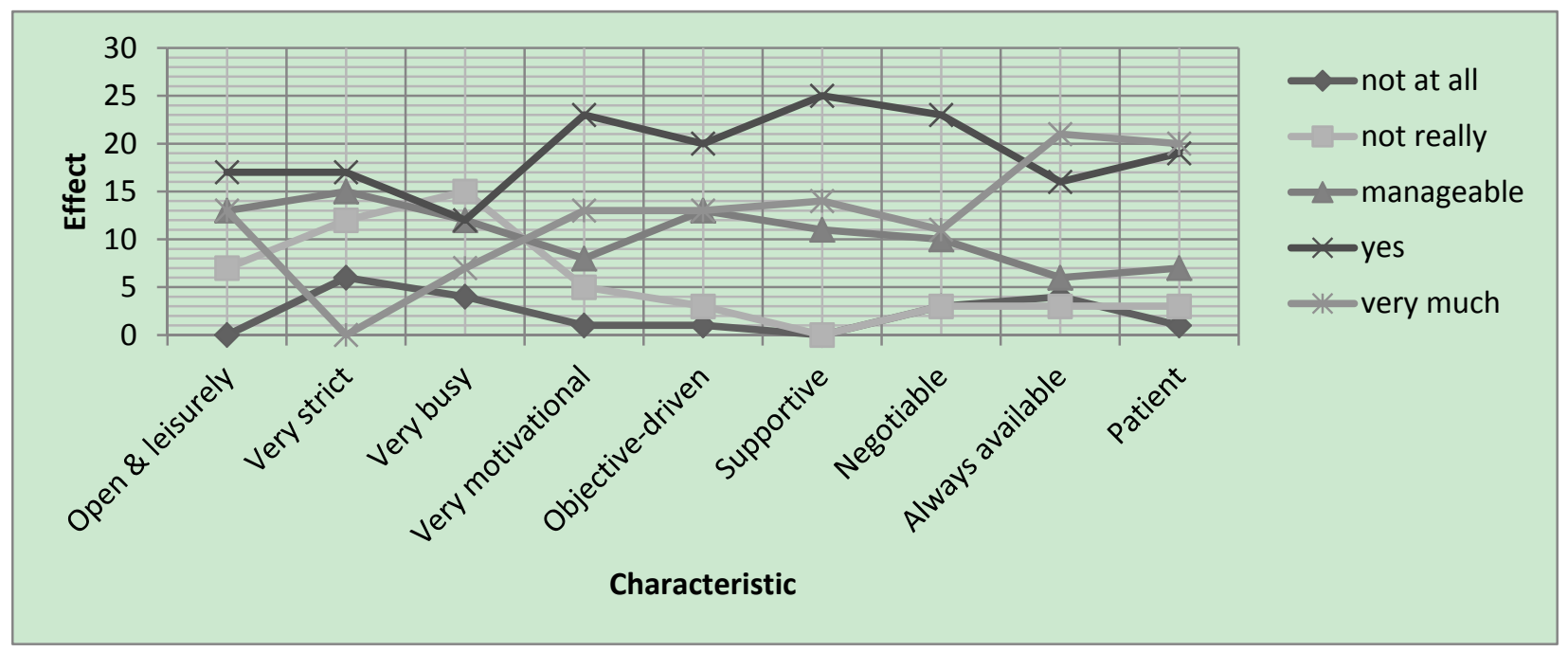

Figure 10. Graph for characteristics in a supervisor of pure science

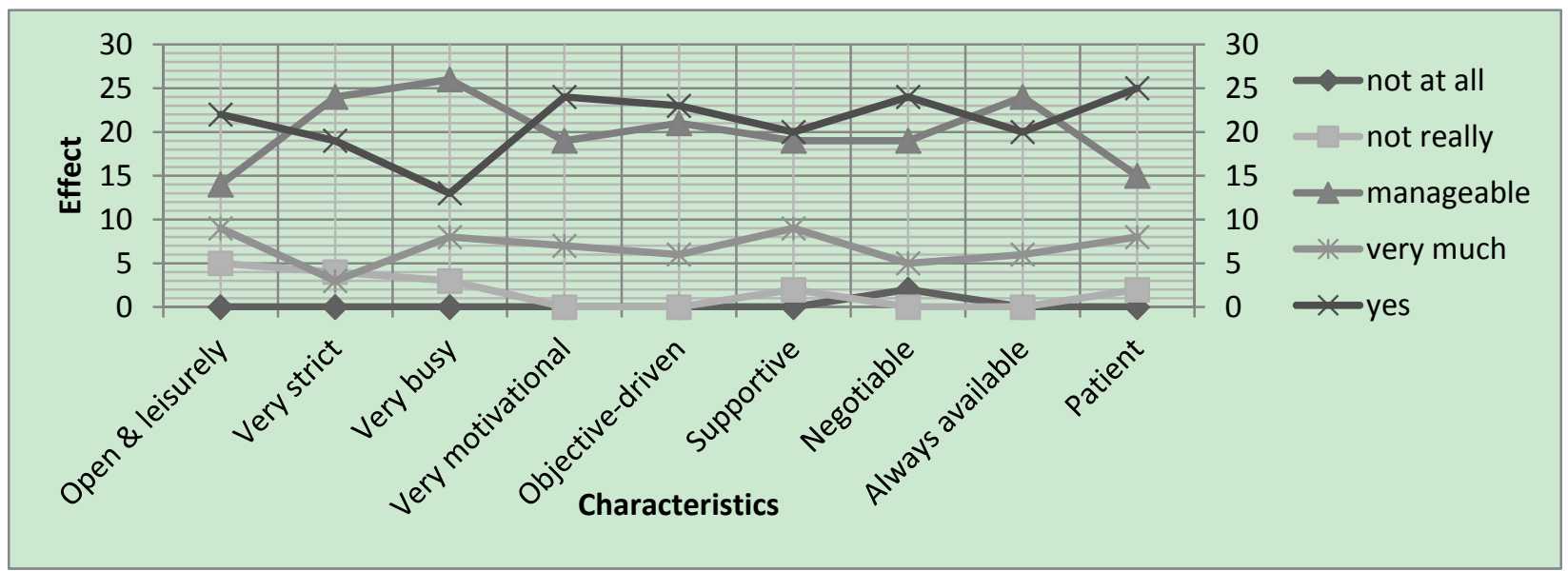

Figure 11. Graph for characteristics in a supervisor of Social Science

Social science shows in Figure 10 has a different result from pure science, and this can be shown in Figure 11. Based on the result, supervisors from social science are very strict and busy but the patient becomes the key features that should have a supervisor. Techniques and methods used in the social sciences are very different from pure science because it does not need a scientific method but mostly depends on the method of oral and writing. Therefore, students not need dependent on the task supervisor but as a monitor for the results research only. So, students in science social show much independent as compare to the student from pure science especially in monitoring and supervision their research activities. Students of social science indicate that the supervisory requirements in their research are different from pure science. Hence, methods to maximize the journal publications are different way. Their research areas example in history, anthropology, psychology and the others more to matters of cultural studies and human relationships do not require them to rely on the methods of a comprehensive supervisory. In conclusion, the characteristics of a good supervisor is depends on the nature and structure of such research, as a pure science is the scientific supervisor and the student need each other to produce an effective investigation for the future, and so too does the social sciences.

\section{Data Analysis for Academic Researcher Survey}

Monitoring and supervising are the most effective method to realize the research university vision as shown in Figure 12 and Figure 13. Monitoring and supervising allow supervisor or academic researcher to guide their students get good result in their research. Therefore, we created a survey to find the methods implemented and techniques applied in their monitoring and supervising. Monitoring and supervising is a requirement in maximizing journal publication. Figure 9 shows the percentage in this case and also know how the method to apply in their research. Refers to the percentage of monitoring and supervising methods implemented, face to 
face process show the higher percentage $29 \%$ and automatically shows that method is very effective. The academic researcher or mentor, research assistant and student will automatically discuss their planning and perform the best research from day to day from this method. Indirectly, the process monitoring and supervising will succeed with the right guidance. Supervisor in the laboratory also very important to guide the students make the laboratory became effective places for students to carry out their research.

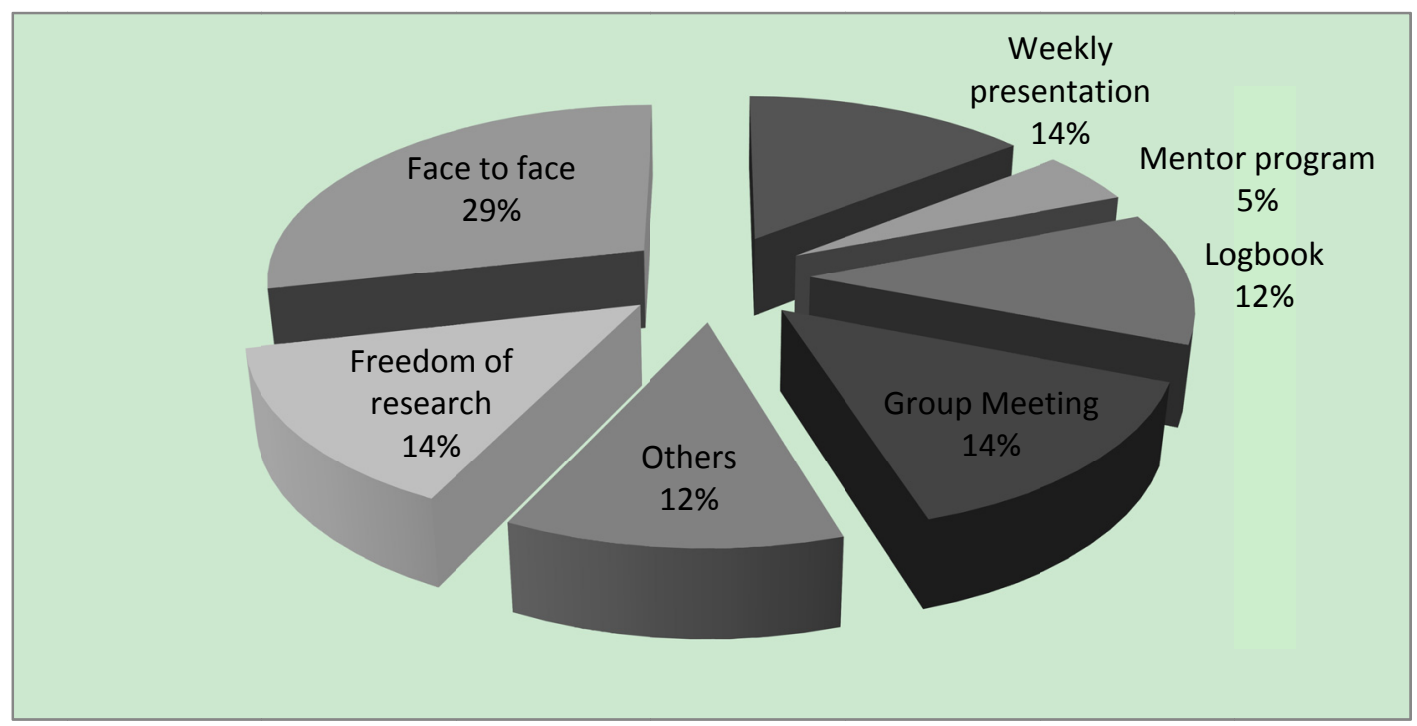

Figure 12. Percentage of monitoring and supervising methods implemented by lectures

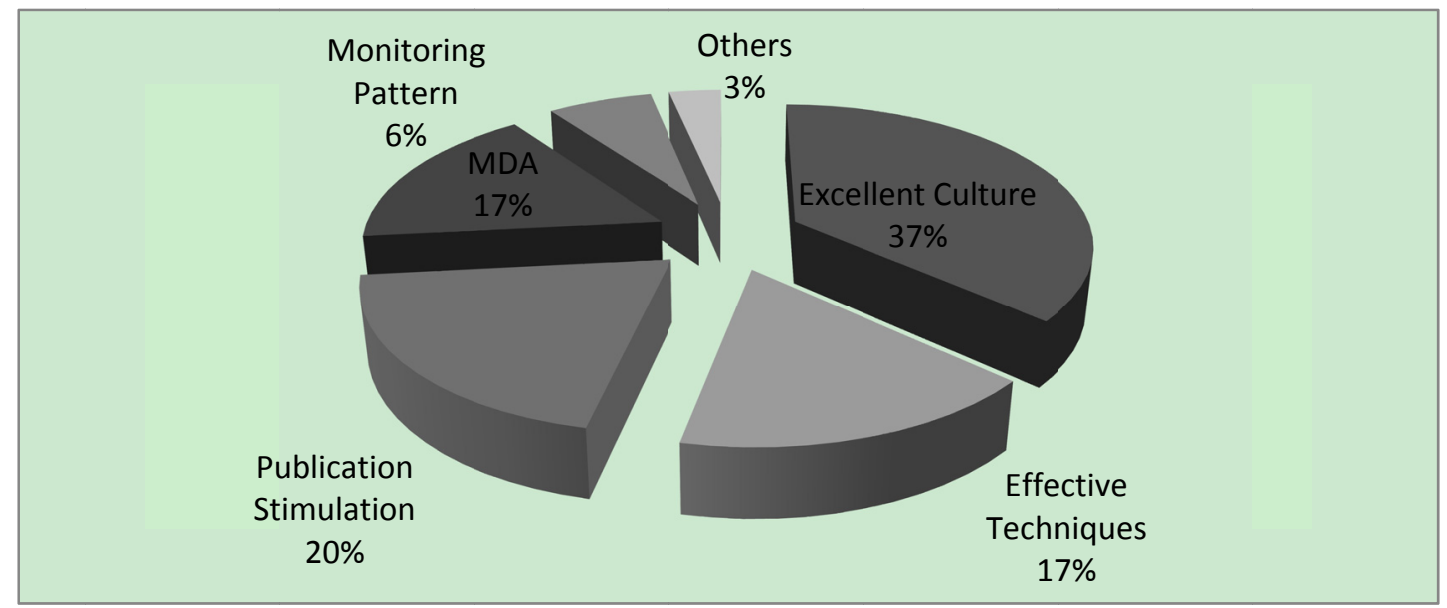

Figure 13. Percentage of techniques applied by academic researchers

Other methods such as weekly presentation (14\%), group meeting (14\%) and freedom of research (14\%) show average percentage and indirectly support this process to guide new researchers. This method implementation showed that supervisor managed their strategy and applied their technique in producing a good researcher or student to maximizing their journal publication. Log book $(12 \%)$, others $(12 \%)$ and mentor program $(5 \%)$ it's the kind of methods implemented in supervising and monitoring.

Based on the survey, percentage of techniques applied by academic researchers showed that excellent culture $(36 \%)$ is the best technique to produce students with high self-motivation. Excellent culture is the best way to make the student and new researcher to get new ideas in their journal writing. Excellent culture includes self-discipline, effective monitoring and provision of facilities in the laboratory (technical and recreational) to make laboratory works more effective for students. Effective techniques (17\%) are also applied by academic researchers in their method. Effective techniques are crucial in maximizing the number of research although the data obtained is little. Inclusion of creative elements is very important in increasing the number and making it unique. The other technique was also applied but its show in the lowers percentage and also supports others. Publication stimulation (20\%) also the higher percentage but MDA, monitoring patterns and others are the most important techniques applied by academic researchers to build a maximizing journal publication. 


\section{Conclusion}

Nowadays, Online Eprint Archives make a dramatically of research publishing articles where can be access by worldwide users without making any request to reprint out peers reviewed articles. This impact make a universities and researchers realize that online access can also enhance their research impact with cited online by peer who reviewed their articles.

The strategy discussed on how to maximize journal publication to others researchers to practically use it. The more quality and quantity of publication published, the more cited will get from peer review the article. In the process of maximizing the publication of journals; universities, supervisor and also students is an important role to realize the dream of hundreds of journal publishing high quality research while helping universities achieves the research university status. Therefore, methods to achieve this mission should be implemented by effective role. Supervisors also serve to provide all facilities to check student's research and research direction for achieved the affective quality and quantity research successfully produced.

\section{Reference}

Baker, E. J. (2004). The pursuit of excellence. Cardiol Young, 14, 1-2. http://dx.doi.org/10.1017/S104795 1104001015

Baldwin, W. L. (1996). The U.S. Research University and the joint venture: Evolution of an institution. Review of Industrial Organization, 11, 629-653. http://dx.doi.org/10.1007/BF00214827

Billing, D. (2004). International comparisons and trends in external quality assurance of higher education: Commonationality or diversity? Higher Education, 47, 113-137. http://dx.doi.org/10.1023/B:HIGH. $0000009804.31230 .5 \mathrm{e}$

Garfield, E. (2006). The History and Meaning of the Journal Impact Factor. JAMA. http://dx.doi.org/10.1001/ jama.295.1.90

Hj. Kamaruzaman Jusoff. (2008). In search of best impact factor and citation indexed journal towards achieving the goals of universities. Journal of Biochemical Technology.

Husu, L., \& De Cheveigne, S. (2010). Gender and gatekeeping of excellence in research funding: European perspectives. Gender Change in Academia, 43-59.

Jeevan, V. K. J., \& Gupta, B. M. (2002). A scientometric analysis of research output from Indian Institute of Technology, Kharagpur. Scientometrics, 53(1), 165-168. http://dx.doi.org/10.1023/A:1014896206968

Kerievsky, J. (2004). Refactor our writings. Lecture Notes in Computer Science, 3092, 321-322. http://dx.doi.org/10.1007/978-3-540-24853-8_51

Kurien, M., Jeyaseelan, L., \& Thomas, K. (1999). Writing a scientific article. Indian Journal of Otolaryngology and Head \& Neck Surgery, 52(1), 2-4.

Maidin, A. B. (2008). Peranan perpustakaan dalam analisis penerbitan IPT: Pengalaman Perpustakaan UKM. In Bengkel analisis jurnal terindeks, 27-28 Ogos 2008, ESSET, Bangi \& Perpustakaan Tun Seri Lanang, UKM, Bangi. (Unpublished).

Maidin, A. B., Kadir, M., \& Mohd Zain, F. (2008). Laporan menghadiri Persidangan Ke-73 IFLA 19-23 Ogos 2007 Durban, Afrika Selatan. In Wacana Program Latihan Perpustakaan UKM, 26 Jun 2008, Bilik Serbaguna Aras 2, PTSL. (Unpublished).

Maidin, A. B., Shafri, S., \& Ibrahim, S. (2009). Perkembangan dan Kemajuan penerbitan jurnal Malaysia: strategi ke persada antarabangsa. In Persidangan Kebangsaan Penerbitan Ilmiah,18-19 April 2009,Pacific Ballroom, Hotel Seri Pacific. (Unpublished).

Peres, P., \& Pimenta, P. (2008). An experiment in collaborative writing. Computers and Education, 53-62.

Siu, K. W. M. (2003). Nurturing All-round Engineering and Product Designers. International Journal of Technology and Design Education, 13, 243-254. http://dx.doi.org/10.1023/A:1026101210221

Ujang, Z. (2007). Pengurusan Masa: Konsep dan Penghayatan. Kuala Lumpur: CERT Publications.

\section{Copyrights}

Copyright for this article is retained by the author(s), with first publication rights granted to the journal.

This is an open-access article distributed under the terms and conditions of the Creative Commons Attribution license (http://creativecommons.org/licenses/by/3.0/). 